\title{
Fotografias aéreas, feições Geomorfológicas, áreas de preservação permanente e megaprojeto de infraestrutura urbana/hoteleira - análise de um trecho da paisagem costeira - Via Costeira de Natal/RN.
}

\author{
Aerial photos, geomorphological features, permanent preservation areas and \\ megaproject of urban/hotel infrastructure - analysis of a stretch of the coastal \\ landscape - Via Costeira Natal/RN.
}

\author{
MELO $^{1}$, M.; CESTARO ${ }^{2}$, L. A.; GALVÃO ${ }^{3}$, F. F. \\ marceudemelo@yahoo.com.br
}

\begin{abstract}
Resumo
O litoral do planeta é considerado ambiente de relativa fragilidade, sustenta diversas atividades econômicas e abriga grande parte da população mundial. $\mathrm{O}$ desenvolvimento da atividade turística no RN está diretamente associada ao litoral e adquiriu maior relevância no final da década de 1970 e início dos anos 1980, no contexto da política dos megaprojetos turísticos, através da implantação do projeto Via Costeira, que objetivava dotar a capital de infraestrutura hoteleira. O projeto gerou muita polêmica, sofreu críticas e reformulações, devido às características naturais da área proposta, majoritariamente coberta por dunas não vegetadas e alguns trechos cobertos por Mata Atlântica, mas foi aprovado. O objetivo deste trabalho foi verificar quais elementos geomorfológicos foram afetados para a implantação do projeto e, a partir destes, delimitar as áreas de preservação permanente (APPs) definidas pela legislação. Os resultados demonstraram que o projeto foi realizado sobre APPs e que a justificativa de utilidade pública é parcialmente questionável, pois havia outras áreas da cidade compatíveis com o uso hoteleiro e o uso social da área pela população local não foi efetivado. Concluímos que a medida mais adequada é declarar os trechos não ocupados como áreas non aedificandi e executar projetos de recuperação das áreas degradadas.
\end{abstract}

Palavras-chave: áreas de preservação permanente, feições geomorfológicas, litoral.

\begin{abstract}
The planet's coastline and is considered an environment of relative fragility, supports several economic activities, shelters a large part of the world's population. The development of tourism activity in the $\mathrm{RN}$ is directly associated to the coast and acquired greater relevance in the 1970s and 1980s, in the context of tourism megaprojects policy, through the implementation of the Via Costeira project, which aimed to provide the capital with hotel infrastructure. The project generated controversies, was criticized and reformulated due to the natural characteristics of the area proposed, mostly covered by non-vegetated dunes and some stretches covered by Atlantic Forest, but it was approved. The objective of this study was to verify which geomorphological elements were affected for the implementation of the project and, from these, to delimit the permanent preservation areas (APP) defined by the legislation. The results showed that the project was carried out on APP and that the justification of public utility is partially questionable, because other areas of the city were compatible with the hotel use and the social use of the area by the local population was not carried out. We conclude that the most appropriate measure is to declare unoccupied stretches as non-aedificandi areas and to carry out recovery projects for degraded areas.
\end{abstract}

Keywords: permanent preservation areas, geomorphological features, coastal

\section{INTRODUÇÃO}

O interesse em realizar um trabalho acerca do litoral surge com a peculiaridade que existe nesse ambiente, um local de interação entre atmosfera, hidrosfera, litosfera, biosfera, e

\footnotetext{
${ }^{I}$ Marceu de Melo, PPGE-UFRN, SEMURB, Natal-RN, Brasil.

${ }^{2}$ Luiz Antonio Cestaro, Departamento de Geografia, Universidade Federal do Rio Grande do Norte, Natal-RN, Brasil.

${ }^{3}$ Frederico Fonseca Galvão, IBAMA, Natal-RN, Brasil.
} 
por ser uma região concentradora de grande parcela da população mundial. Metade das cidades mundiais com mais de um milhão de habitantes está localizada à beira-mar (DREW, 2011, p. 128). No caso brasileiro, o litoral está vinculado ao "descobrimento", ponto de partida da história do nosso país no cenário mundial, com cerca de $8.500 \mathrm{~km}$ de extensão, compreendendo $4,1 \%$ da sua área territorial, abrangendo aproximadamente 300 municípios e abrigando $24,6 \%$ da população total do Brasil, valor um pouco inferior a 48 milhões de habitantes (IBGE, 2011, p. 89 e 124).

Significativa parcela da população dos municípios costeiros do Brasil está ocupada em atividades, direta ou indiretamente, ligadas ao turismo, à produção de petróleo e gás natural, à pesca e a serviços associados à dinâmica econômica dessas atividades (IBGE, 2011, p. 117).

A importância do turismo pode ser explicada pelo fato de durante a década de 1980, o Brasil, nas esferas federal, estadual e municipal, ter investido fortemente no desenvolvimento de uma série de políticas públicas com o objetivo de alavancar essa atividade, especialmente na orla marítima de várias capitais brasileiras (SOUZA, 2008, p. 657). Natal foi contemplada com essas políticas através da implantação do megaprojeto turístico Parque das Dunas/Via Costeira, também denominado apenas projeto Via Costeira.

A implantação do projeto Via Costeira recebeu uma série de críticas e foi alvo de muitas polêmicas, desde as relacionadas à própria concepção do projeto (construir uma cópia da orla de Copacabana/RJ) até a degradação ambiental de uma área com significativa importância na paisagem, na qualidade hídrica do município e na preservação da vegetação das dunas (SOUZA, 2008).

A mobilização da sociedade natalense resultou na modificação de alguns aspectos do projeto Via Costeira que teve sua implantação iniciada no final dos anos 1970 contudo, ainda hoje levanta uma série de questões e divergências relacionadas aos tipos de uso e ocupação permitidos e adequados para a área.

O objetivo deste trabalho foi identificar e especializar as feições geomorfológicas existentes na área de estudo antes do início da implantação do projeto Via Costeira (1978), e em seguida verificar quais feições foram afetadas pela implantação, fazendo também considerações à legislação que dispunha e dispõe sobre as Áreas de Preservação Permanente (APPs) e propondo a declaração das áreas não ocupadas como non aedificandi, bem como a recuperação das mesmas.

Este trabalho contemplou um trecho do ambiente costeiro da cidade de Natal/RN conhecido como Via Costeira, com os seguintes limites: oeste - Avenida Senador Dinarte 
Mariz, integrante da rodovia RN-301; leste - Oceano Atlântico; norte - praia de Areia Preta; sul - praia de Ponta Negra, ver Figura 01.

\section{METODOLOGIA}

Na elaboração deste trabalho foram utilizados dois levantamentos aerofotogramétricos:

1. Fotografias aéreas e curvas de nível da SEPLAN/IDEC de 1978, fotografias na escala 1:2.000, em preto e branco, não Georreferenciadas;

2. Fotografias aéreas da SETUR/SIN/IDEMA de 2006, escala 1:2.000, coloridas e Georreferenciadas em UTM, datum SAD69.

As imagens de 1978 foram Georreferenciadas tendo como base as imagens de 2006. O mosaico das imagens de 2006 foi obtido junto à Secretaria Municipal de Meio Ambiente e Urbanismo de Natal.

Utilizamos o software ArcGIS 10.1 para o Geoprocessamento realizado neste trabalho.

Os procedimentos cartográficos realizados estão resumidos graficamente na Figura 02.

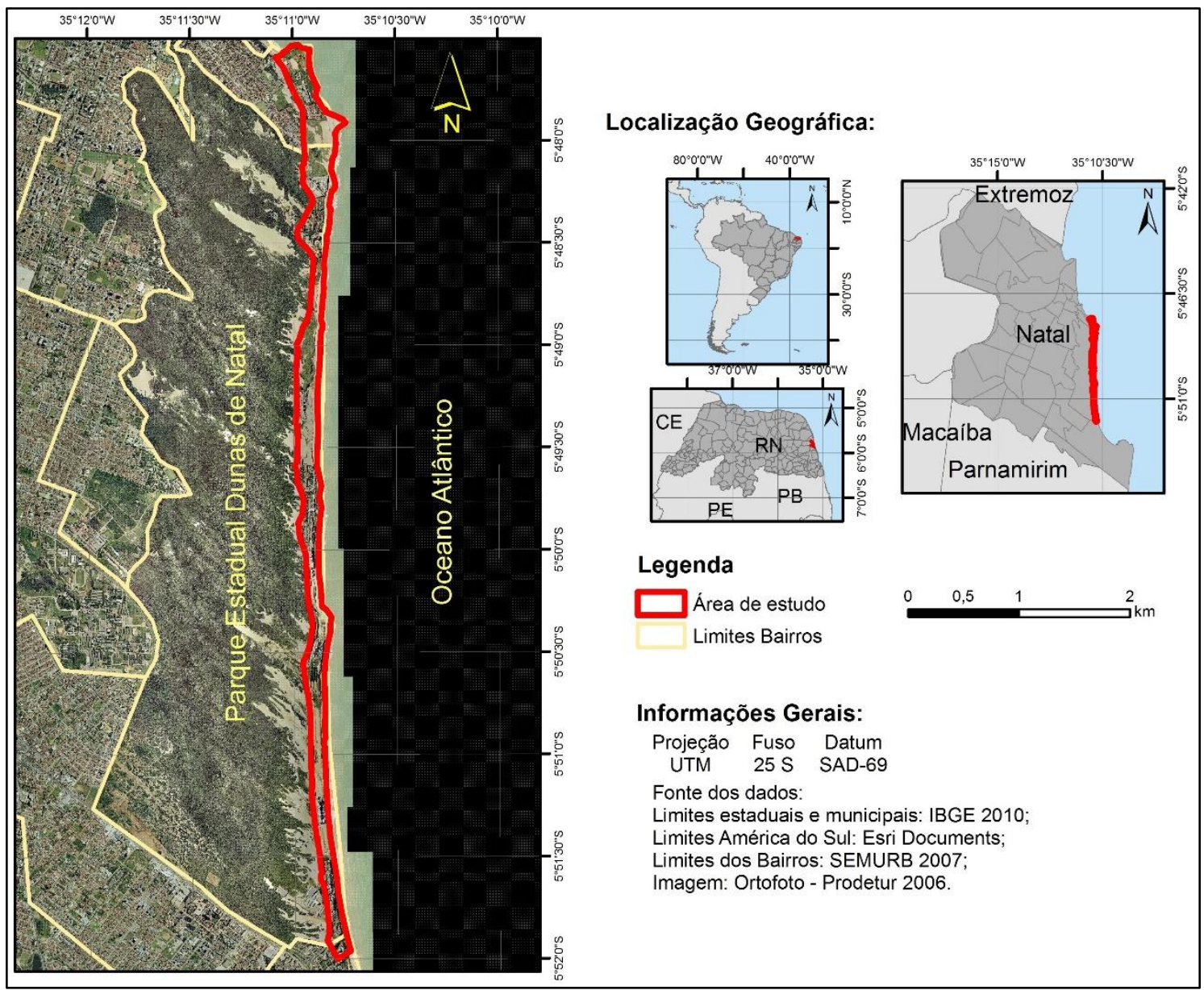

Figura 01. Mapa de localização da área de estudo. Fonte: Melo (2017). 
Optamos por manter as imagens de 1978 unidas através do georreferenciamento (ver Figura 03), ao invés de usar o mosaico, pois o resultado conseguido com o mosaico não foi satisfatório. A restituição temática foi feita manualmente pelo método digitalização em tela.

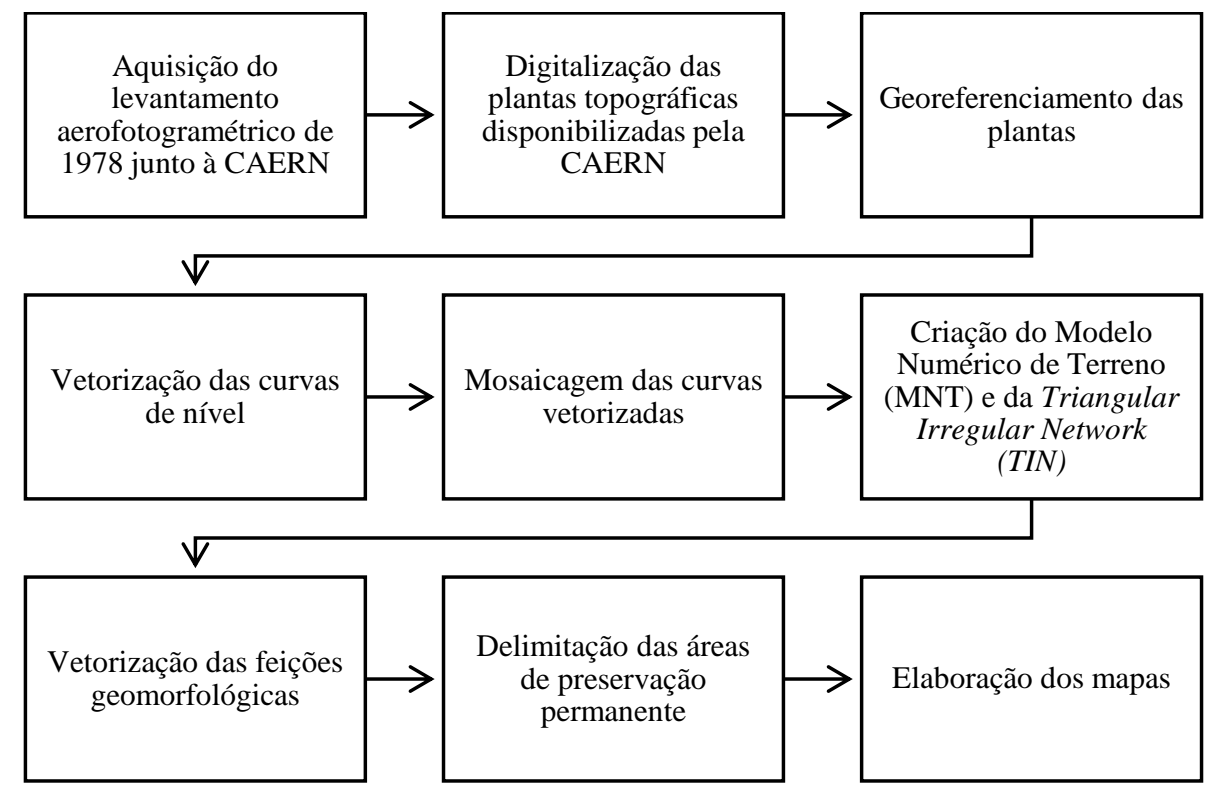

Figura 02. Fluxograma do processo cartográfico. Fonte: Autores (2014).

A identificação e delimitação das feições Geomorfológicas foi realizada a partir de fotointerpretação e vetorização nas imagens do levantamento aerofotogramétrico da SEPLAN/IDEC de 1978. Até o ano de 1978 a área mantinha condições próximas ao natural, pois a área era pouquíssimo frequentada pela população e as grandes intervenções que contribuíram para a descaracterização Geomorfológica e edáfica ainda não haviam sido realizadas.

A identificação das feições Geomorfológicas na área de estudo se pautou nos conceitos citados abaixo.

Para praia adotamos a definição proposta por:

Zona perimetral de um corpo aquoso (lago, mar ou oceano), composta de material inconsolidado, em geral arenoso $(0,062$ a $2 \mathrm{~mm})$ ou mais raramente composta de cascalhos ( 2 a $60 \mathrm{~mm}$ ), conchas de moluscos, etc., que se estende desde o nível de baixa-mar média (profundidade de interação das ondas com o substrato) para cima, até a linha de vegetação permanente (limite de ondas de tempestade), ou onde há mudanças na fisiografia, como as zonas de dunas ou de falésias marinhas (sea cliffs)... Uma praia abrange a antepraia (foreshore) ou praia entremarés (intertidal beach) e a pós-praia (backshore) ou praia seca (dry beach), não fazendo parte dela as formas e os depósitos de areia permanentemente submersos. (SUGUIO, 1998, p. 625) 
Este trabalho considerou as falésias como encostas costeiras íngremes, geralmente com mais de $40^{\circ}$ de inclinação, ou seja, caracterizadas por declives íngremes que aumentam abruptamente a partir da água ou a partir da parte de trás de uma plataforma que é suficientemente estreita para que a base do talude seja afetada pela ação da onda durante tempestades, normalmente cortadas em formações rochosas e recuando em decorrência da erosão marinha na sua base, acompanhada pela erosão subaérea (ARNOTT, 2010, p. 396; BIRD, 2008, p. 67) .

As falésias podem ser classificadas de acordo com a exposição ou não à ação da erosão marinha (ondas e marés) encontramos na literatura os seguintes termos, respectivamente: falésia ativa ou viva; e falésia inativa, fóssil, morta, abandonada e paleofalésia (AB'SÁBER, 2005, p. 5; IBGE, 1999, p. 81 e 82; MAYHEW, 2004, p. 89; JATOBÁ e LINS, 1998, p. 124; SUGUIO, 1998, p. 331). Nas Figuras 04, 05 e 06 vemos exemplos de falésias na área de estudo. 


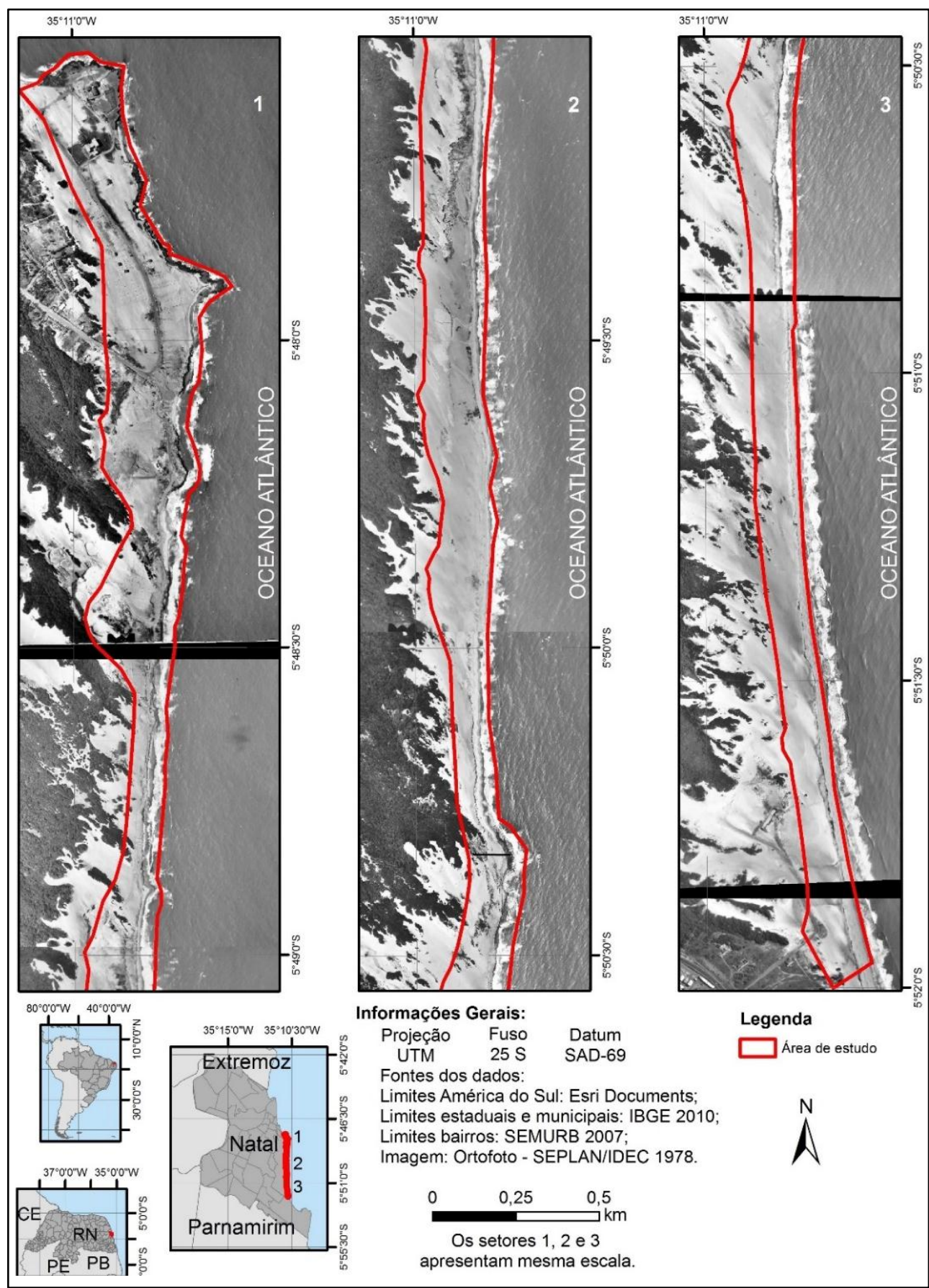

Figura 03. Fotografias aéreas de 1978 (SEPLAN/IDEC) da área de estudo. Fonte: Melo (2017).

Bird (2008, p. 69 e 77) apresenta uma classificação pautada no tamanho das falésias. As menores são chamadas low cliffs (clifflets ou microcliffs), o autor não especificou a medida destas, mas os exemplos que ele apresenta estão em torno de 1 a 2 metros de altura; a partir destas até 100 metros acima do nível do mar temos cliffs; entre 100 e 500 metros acima do nível do mar são chamados de high cliffs; e aquelas superiores a 500 metros são chamados megacliffs. Esta classificação é importante para os objetivos deste trabalho, pois alguns defendem que as falésias de pequena altura não devem ser consideradas, visando diminuir os 
elementos elencados como APP, no entanto, tal proposição não se sustenta, conforme o conceito aqui apresentado.

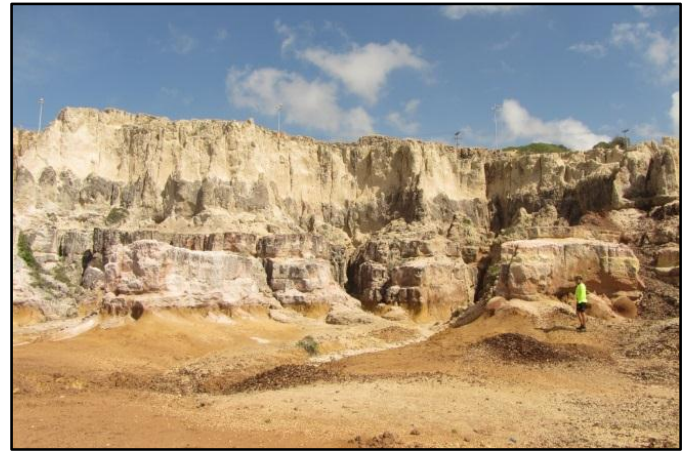

Figura 04. Falésias inativas na área de estudo. Fonte: Melo (2014).

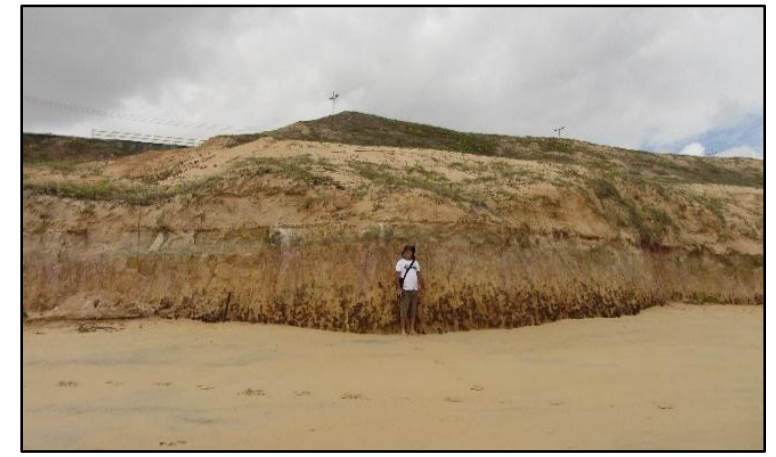

Figura 05. Praia arenosa encerrada em falésia ativa. Fonte: Melo (2014).

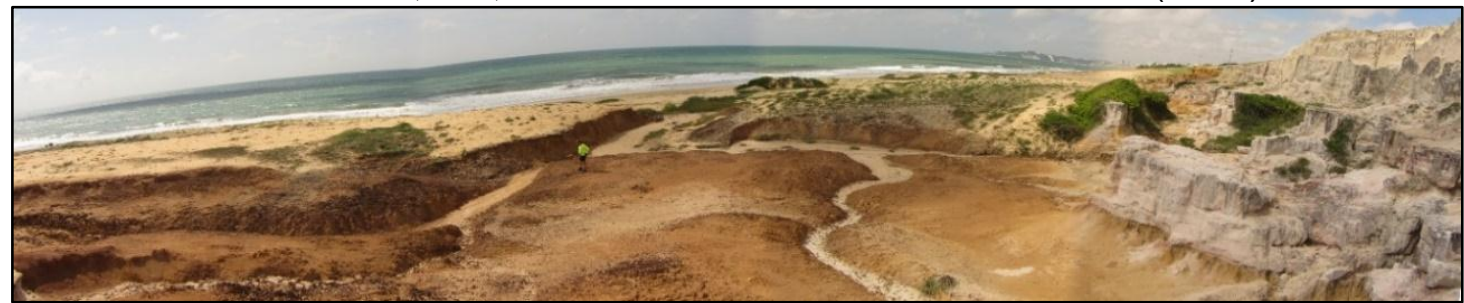

Figura 06. Falésias inativas (canto direito da imagem) e depósitos de talude com marcas dos cursos d'água formados em épocas de chuvas (atual fator erosivo preponderante). Fonte: Melo (2014).

Sobre os recifes de arenito, comuns na cidade do Natal, Guerra e Guerra (1997, p. 517) dizem que "resultam da cimentação de antigas praias, isto é, dos grãos de quartzo outrora incoerentes. Distinguem-se dos recifes de corais, que são organógenos. Alguns usam como sinônimo de recife de pedras". O autor informa que o cimento aglutinador dos grãos de areia pode ser ferruginoso ou calcário.

Ab'Sáber (2005, p. 40) informa que as rochas que mantêm o recife arenítico têm sido designadas por beach rock, caracterizadas como herança de paleopraias subatuais litificadas, em alguns recifes existe uma muralha de arenito ou de setores coralíngenos alinhados, na maré baixa afloram parcialmente e nas marés altas atuam como faixas de arrebentação, formando alongadas piscinas naturais e atenuando a dinâmica das praias atuais. Essa função dos recifes na atenuação da dinâmica costeira é bem visível na área de estudo.

Sobre a formação dos beach rocks, Bird (2008, p. 161) a associa à precipitação de carbonatos na zona do lençol freático flutuante dentro de uma praia (relacionado com a subida e descida das marés e alternâncias de clima úmido e seco) que pode cimentar a areia da praia em duras camadas de arenito conhecidas como beach rocks.

Para Suguio (1998, p. 657) o termo recife rochoso abrange os recifes formados "por rochas inorgânicas, principalmente arenitos (sandstones) e conglomerados (conglomerates), 
em contraposição ao recife orgânico (organic reef)". Neste trabalho, a partir desse conceito de Suguio, agrupamos os recifes de arenitos e recifes de conglomerados em uma única categoria, devido à dificuldade de diferenciação de ambos nas imagens.

Faz-se oportuno diferenciar as rochas de praia (beach rocks) das rochas na praia, ou seja, as rochas que se formaram na praia e as que chegaram até à praia por processos de erosão ou deposição. Durante a fase de revisão da literatura sobre a área de estudo percebemos certa confusão na identificação das rochas encontradas no ambiente praial e analisando mais detalhadamente, com auxílio de referencial bibliográfico consultado, observamos que algumas feições definidas como beach rocks são na verdade arenitos ferruginosos provenientes do processo de erosão do afloramento costeiro do Grupo Barreiras que foram retrabalhados pela ação dos diversos processos atuantes na dinâmica costeira (vento, ondas, marés, salinidade, etc). É possível perceber facilmente a diferença pois, os beach rocks apresentam estratificação sub-paralela cruzada desenvolvida pelo processo de formação apresentado anteriormente, enquanto que os arenitos ferruginosos não apresentam estratificação, são selecionados e remobilizados pela ação das ondas e marés.

A Figura 07 permite visualizar os arenitos ferruginosos em um dos trechos de ocorrência na área de estudo. Podemos observar o material que originará os arenitos ferruginosos ainda consolidados, compondo a falésia esculpida no afloramento do Grupo Barreiras, enquanto que outros foram desagregados através dos processos erosivos e estão à disposição da dinâmica costeira, da base da falésia até o oceano, parcialmente cobertos pela areia. As Figuras 08, 09 e 10 mostram exemplos de ocorrência de beach rocks na área de estudo.

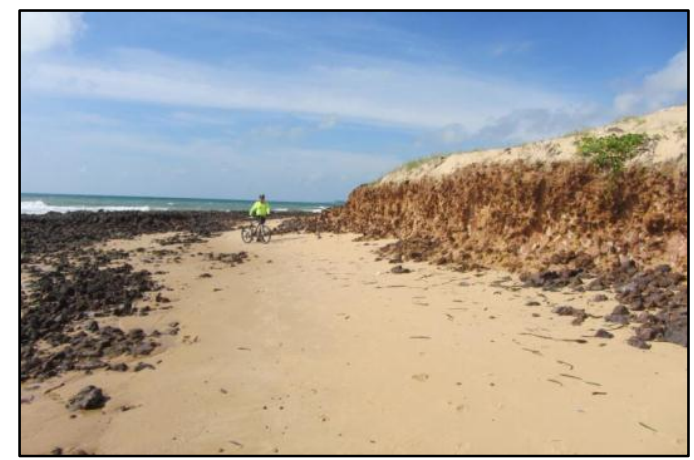

Figura 07. Arenitos integrando a falésia e arenitos ferruginosos sob ação costeira. Fonte: Melo (2014).

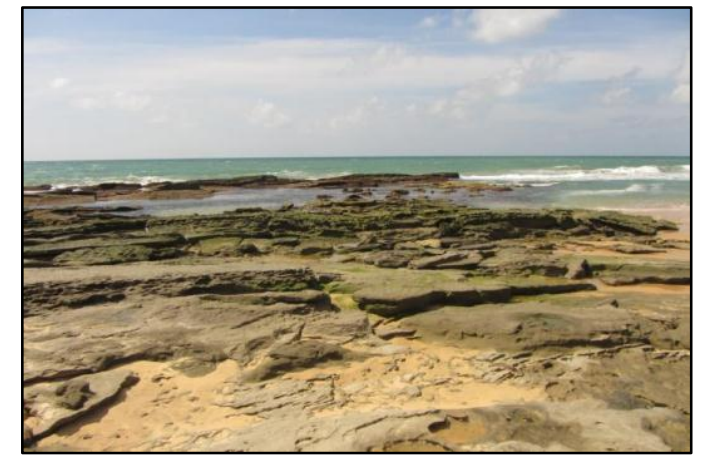

Figura 08. Um dos pontos de ocorrência de beach rocks na área de estudo. Fonte: Melo (2014). 


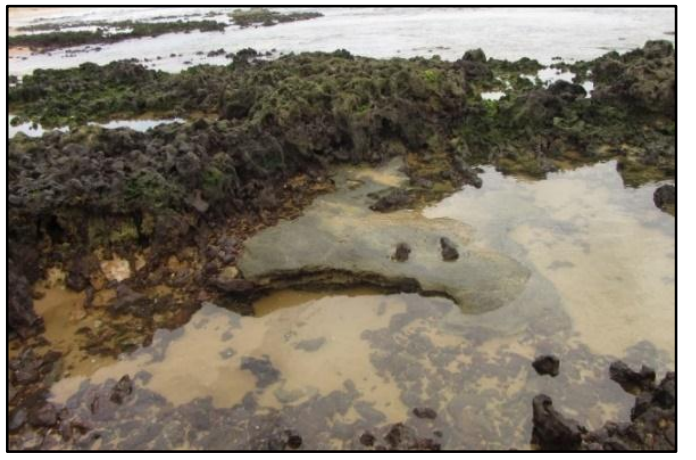

Figura 09. Beach rock (superfície plana no centro da foto) e arenitos ferruginosos (conglomerados de rochas de cor escura). Fonte: Melo (2014).

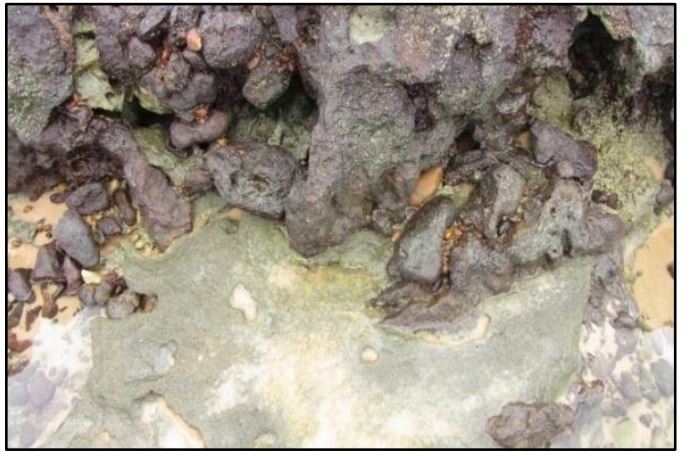

Figura 10. Detalhe da foto anterior, beach rock formado agregando arenitos ferruginosos.

Fonte: Melo (2014).

Livingstone e Warren (1996, p. 65) conceituam as dunas como acúmulos de sedimentos arenosos que foram transportados pelo vento e moldados em formas de leito por deflação e deposição. Os autores fazem ressalvas significativas sobre estas feições, uma delas é muito útil para a discussão proposta, pois está relacionada à escala. Livingstone e Warren op. cit. observaram que no extremo inferior existe o risco de confundir dunas com ondulações (ripples) e no extremo superior com campos de dunas (dunefields) ou mares de areia (sand seas), para evitar essa confusão, os autores limitam as dunas como feições com dimensões aproximadas entre 0,3 - 400 metros de altura e de 1,0 - 500 metros de largura, mas informam que ainda pode haver sobreposição entre estas dimensões propostas para as dunas e as ondulações e campo de dunas. As figuras 11 e 12 mostram exemplos de dunas com ocorrência da área de estudo.

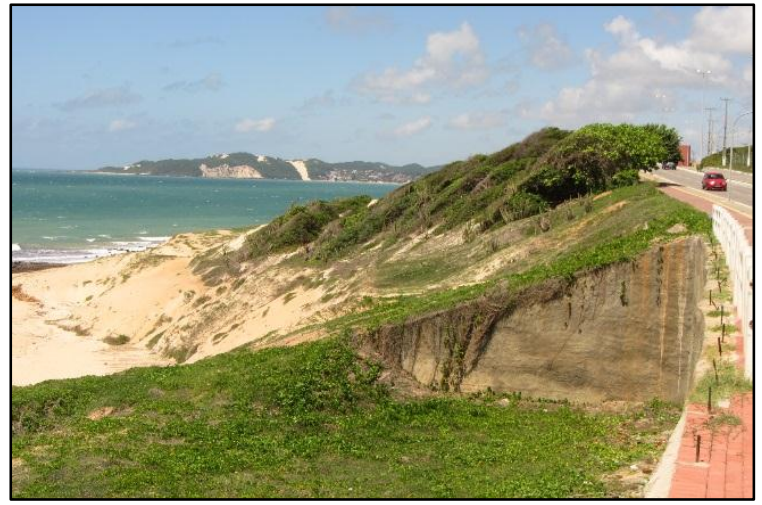

Figura 11. Duna vegetada com diferentes estratos (herbáceo, arbustivo e arbóreo). Fonte: Melo (2014).

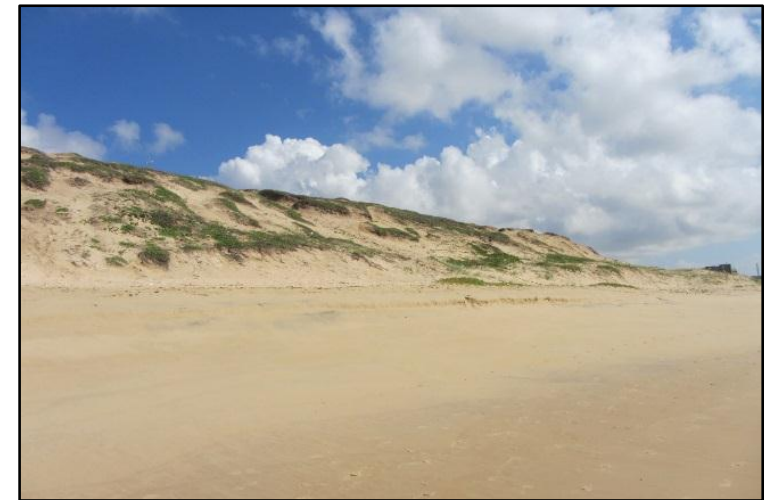

Figura 12. Duna com vegetação herbácea esparsa. Fonte: Melo (2014).

Considerando as definições apresentadas e os objetivos deste trabalho, a metodologia sistêmica aplicada à Geografia Física aparece como a mais indicada para estudar as questões aqui propostas. 
Neste estudo foi adotado o conceito de sistema, apoiado em Bertalanffy (1975), Rodriguez et al. (2007) e Wicander e Monroe (2011), entendendo que ao dividir o todo em componentes menores a observação dos elementos e a visualização de suas interações é facilitada, no entanto, sem perder de vista a totalidade (complexa, única e organizada), pois existem qualidades próprias ao sistema que se somam àquelas inerentes aos elementos que o formam. E considerando a paisagem não como uma "simples adição de elementos geográficos disparatados", mas sim, "em uma determinada porção do espaço, o resultado da combinação dinâmica, portanto instável, de elementos físicos, biológicos e antrópicos que, reagindo dialeticamente uns sobre os outros, fazem da paisagem um conjunto único e indissociável, em perpétua evolução". (BERTRAND, 2004, p. 141).

\section{RESULTADOS E DISCUSSÕES}

A partir dos conceitos anteriormente apresentados e da utilização das imagens do levantamento aerofotogramétrico de 1978, foram identificadas e delimitadas as feições geomorfológicas da área de estudo, conforme Figura 13. A escala utilizada na vetorização (1:2.000) e a criação do MNT e da TIN facilitaram essa identificação. 


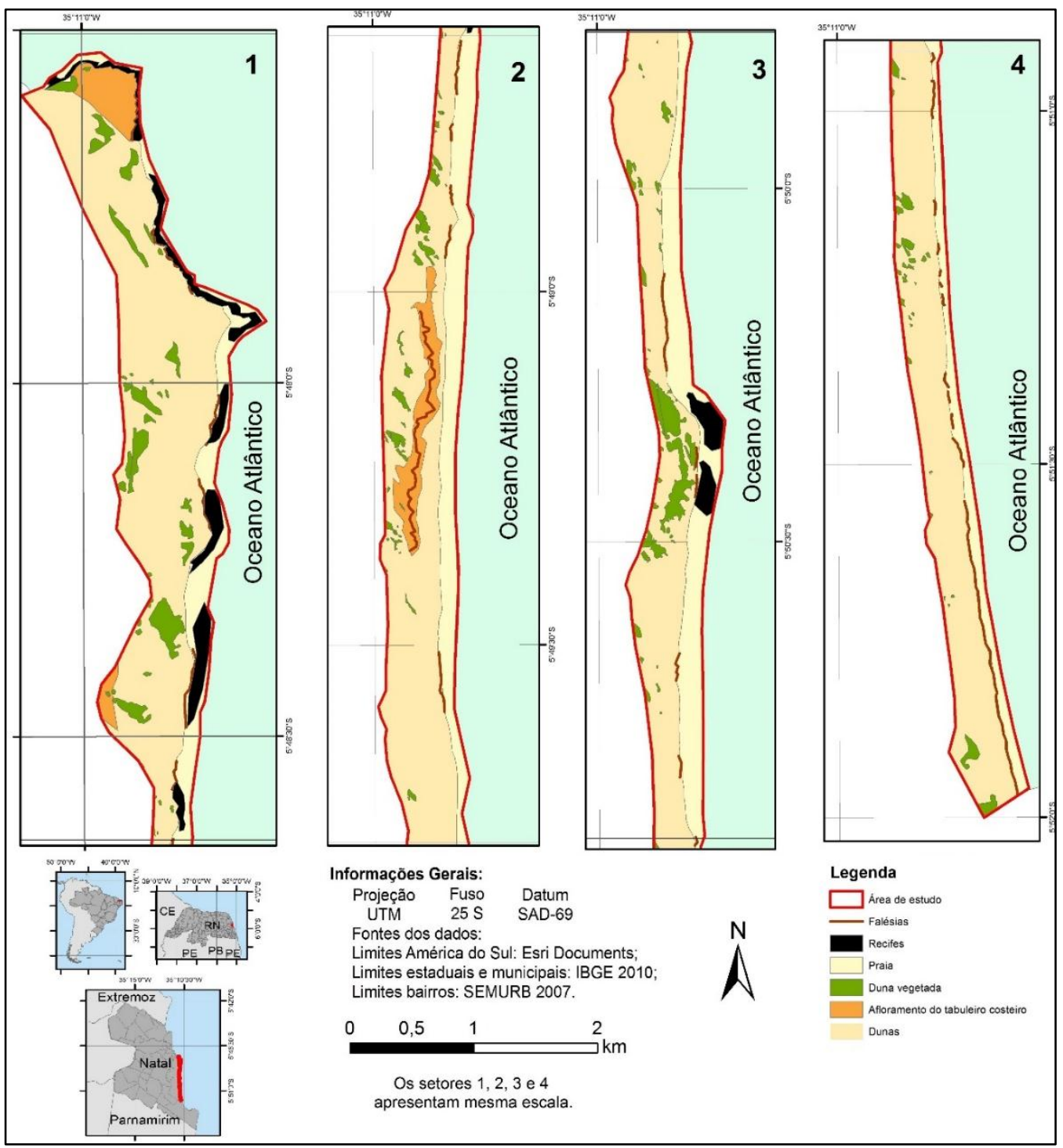

Figura 13. Feições geomorfológicas da área de estudo em 1978. Fonte: Melo (2014).

Sabemos que a delimitação precisa da feição praia necessita de um conjunto de imagens de períodos de tempo diferentes que permitam visualizar a variação das marés, no entanto, a delimitação aproximada realizada atende aos objetivos deste trabalho. A delimitação dessa feição se pautou na visualização de mudança fisiográfica em direção ao continente.

Como os recifes ficam permanentemente e/ou parcialmente submersos, a vetorização desta feição é apenas uma aproximação da realidade, a partir dos trechos onde foi possível sua visualização. Além da dinâmica das ondas e marés, outro elemento importante na visualização e delimitação dos recifes é a dinâmica dos sedimentos (erosão/deposição), que também pode recobrir ou expor estas feições.

Ressalva também deve ser feita quanto às falésias, estas feições podem ser recobertas pelos sedimentos arenosos de acordo com a intensidade dos ventos e disponibilidade de 
sedimentos, estando a exposição destas feições associada dinâmica costeira. A delimitação das falésias feita neste trabalho se pautou na situação registrada nas imagens aéreas de 1978.

Durante o processo de implantação do Projeto Via Costeira, de 1977 a 1993, a legislação ambiental adicionou novas áreas consideradas de preservação permanente, especialmente no âmbito municipal. Estava em vigência o Código Florestal de 1965 e foram aprovados os Planos Diretores Municipais de 1974 e 1984, como também houve a promulgação do Código de Meio Ambiente do Município em 1992.

O Quadro 01 foi elaborado com o objetivo de demonstrar quais elementos naturais existentes na área de estudo eram considerados APPs durante a fase de implantação do Projeto Via Costeira.

Quadro 01. Condição dos elementos naturais da Via Costeira segundo a legislação, onde APP = Área de Preservação Permanente. Fonte: Melo (2014).

\begin{tabular}{c|c|c|c|c|c}
\hline Elemento natural & $\begin{array}{c}\text { Duna } \\
\text { vegetada }\end{array}$ & $\begin{array}{c}\text { Duna não } \\
\text { vegetada }\end{array}$ & $\begin{array}{c}\text { Borda de } \\
\text { tabuleiro }\end{array}$ & Recife & Falésia \\
$\begin{array}{c}\text { Código Florestal } \\
\text { 1965 }\end{array}$ & APP & APP & & \\
\hline Plano Diretor 1974 & APP & & & & \\
\hline Plano Diretor 1984 & & APP & & & \\
\hline $\begin{array}{c}\text { Código de Meio } \\
\text { Ambiente 1992 }\end{array}$ & APP & APP & & APP & APP \\
\hline
\end{tabular}

Diante das informações apresentadas no Quadro 01 visualizamos três contextos legais para a ocupação da Via Costeira:

- Primeiro contexto legal - no início da implantação do Projeto Via Costeira apenas o Código Florestal de 1965 e o Plano Diretor de Natal de 1974 estavam em vigor, esses instrumentos atribuíam a preservação permanente apenas às dunas vegetadas e às bordas de tabuleiros/falésias;

- Segundo contexto legal - o Plano Diretor de 1984 atribuiu proteção às dunas migrantes (dunas móveis, expostas ou não vegetadas), ampliando significativamente a área considerada de preservação permanente, pois as dunas migrantes são as feições mais representativas da área de estudo;

- Terceiro contexto legal - o Código de Meio Ambiente do Município do Natal de 1992 garantiu proteção às falésias e aos recifes, dentre outros elementos. A proteção aos recifes como APPs não interfere na ocupação da Via Costeira, pois estas feições estão 
inseridas na área coberta periodicamente (zona de estirâncio) ou constantemente pelas marés (antepraia), subambientes da praia.

Assim, as dunas expostas, as dunas vegetadas, as falésias e os recifes passaram a receber proteção legal, sendo declarados áreas de preservação permanente, tornando APP praticamente toda a extensão da área de estudo, conforme apresentado na Figura 14, excetuando-se apenas o afloramento do tabuleiro costeiro. A Figura 15 destaca todas as APPs na cor vermelha para efeito visual. As áreas definidas como "ocupação consolidada" se referem aos hotéis, locais de eventos, prédios institucionais e similares.

O Quadro 02 mostra os atuais instrumentos legais que estabelecem as APP. Há uma discussão quanto à permanência da vigência da Resolução CONAMA no 303/2002 após a promulgação do Novo Código Florestal (Lei Federal n ${ }^{\circ}$ 12.651/2012). Alguns defendem que a Resolução foi revogada, pois regulamenta uma Lei revogada, no entanto, outros advogam a permanência da Resolução em caráter complementar. O CONAMA não indicou a revogação da Resolução e a decisão quanto à sua utilização segue dividindo opiniões e gerando polêmica. Decidimos por manter a Resolução CONAMA nº 303/2002 junto aos instrumentos legais em vigor, além do mais, a especulada revogação da mesma não implicaria perda de proteção aos ambientes da área de estudo, pois estão previstos em outros dispositivos legais.

Quadro 02. Áreas de Preservação Permanente ou Áreas de Preservação $^{1}$ com ocorrência na Via Costeira e os instrumentos legais que assim as define. Fonte: Melo (2014).

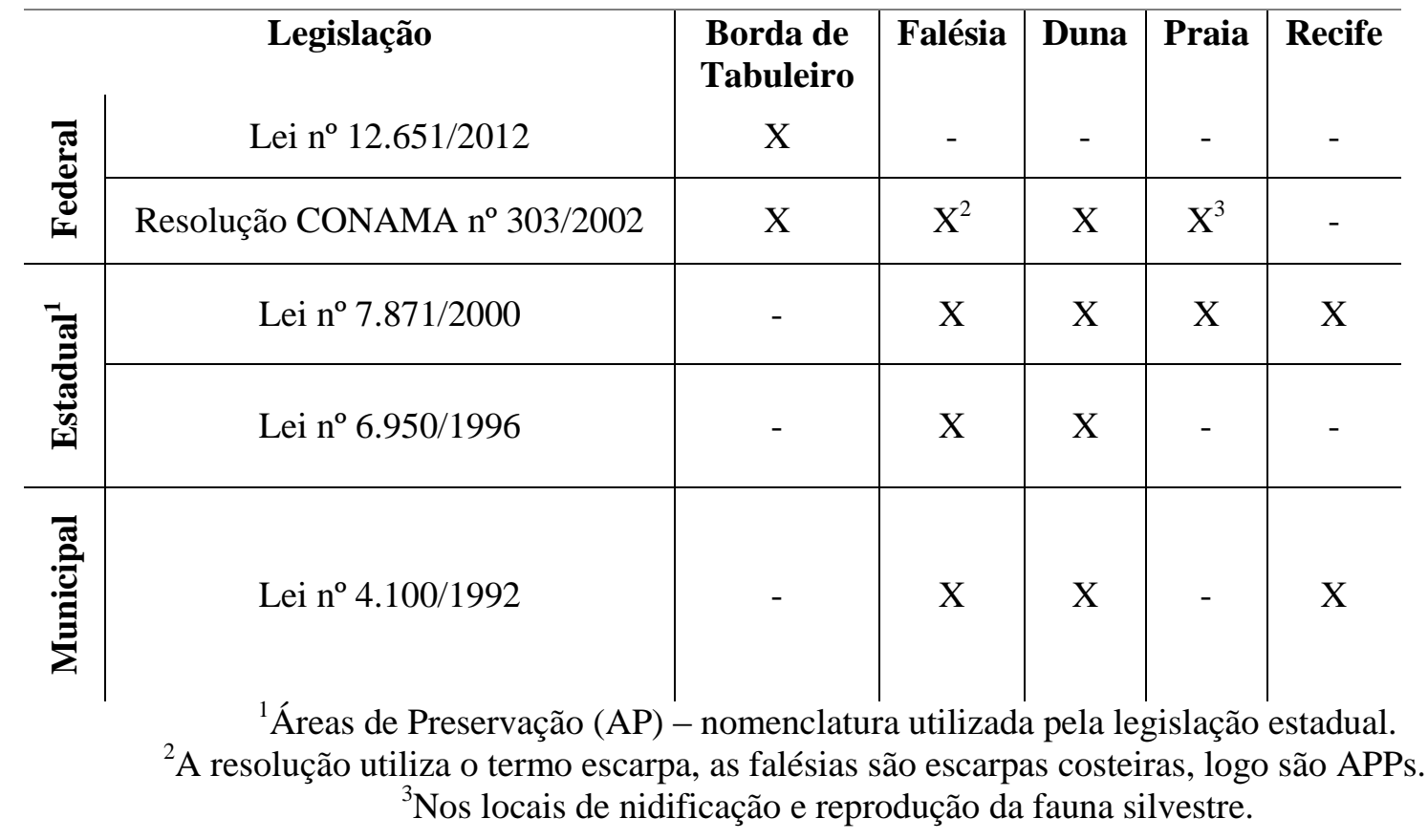




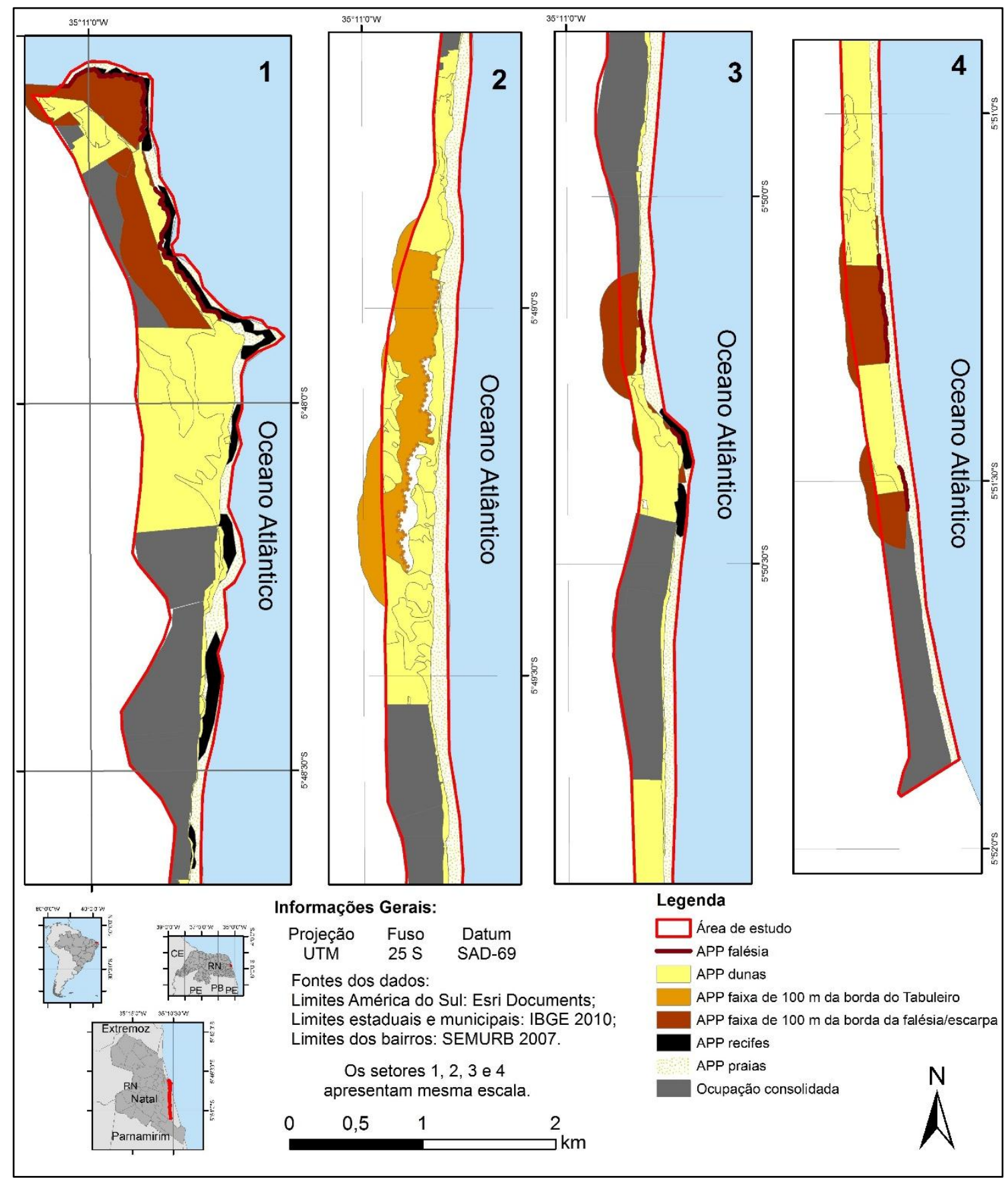

Figura 14. Áreas de Preservação Permanente na área de estudo, conforme Quadro 02. Fonte: Melo (2017). 


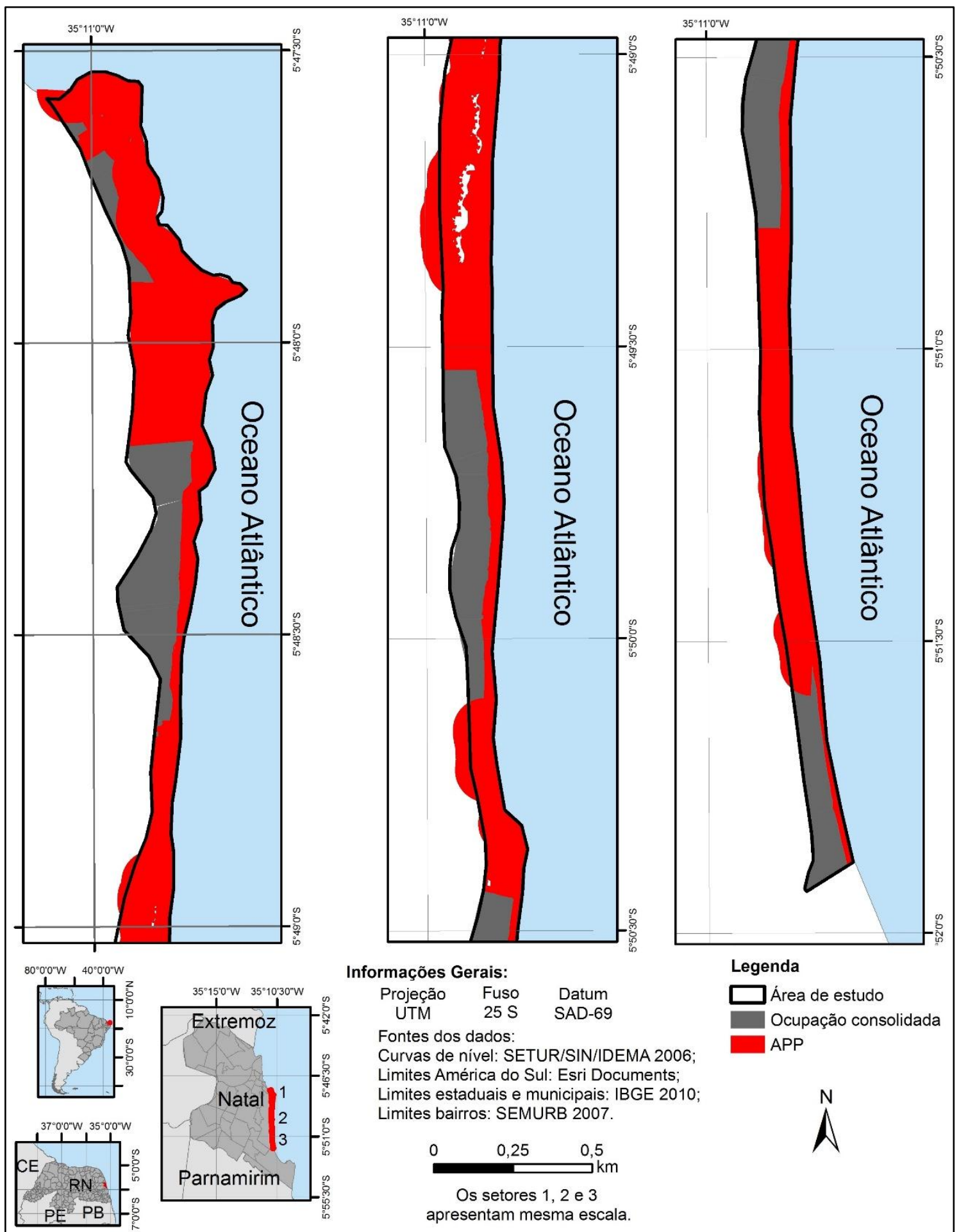

Figura 15. Áreas de Preservação Permanente da área de estudo destacadas em vermelho. Fonte: Melo (2017).

\section{CONSIDERAÇÕES FINAIS}

A identificação e espacialização das feições geomorfológicas possibilitou verificar a área de estudo em uma situação mais próxima ao natural, ou seja, antes da descaracterização 
geomorfológica e edáfica provocada pelas grandes intervenções relacionadas ao Projeto Via Costeira, sendo essencial na identificação e delimitação das áreas consideradas de preservação permanente, pois muitas destas feições são elementos de preservação.

O levantamento realizado sobre a legislação federal, estadual e municipal que trata das áreas de preservação permanente foi fundamental para confrontar a implantação do Projeto Via Costeira e os aspectos legais. Os instrumentos legais pesquisados mostraram que as áreas consideradas de preservação permanente foram ampliadas ao longo do tempo, atribuindo preservação a ambientes que possuem importância na garantia das funções ambientais.

Destacamos a necessidade da sociedade civil manter-se atenta às alterações propostas à legislação ambiental nas diferentes esferas do poder para que estes importantes elementos não percam a proteção legal que ainda lhes é garantida.

Acreditamos que a implantação do Projeto Via Costeira como obra de utilidade pública é justificada no que se refere à rodovia $\mathrm{RN}-301$, pois se tornou uma importante via de ligação da cidade.

Quanto a justificativa de utilidade pública promovida pela geração de emprego e renda através da ocupação hoteleira nas APPs, apesar de ter alavancado a atividade turística, é questionável, pois estas não eram as únicas áreas desocupadas no município. Os hotéis poderiam ter sido implantados em outras áreas da cidade, como Ponta Negra, Areia Preta, Praia do Meio, etc. Ou, no mínimo, as ocupações poderiam ter sido distribuídas pelas áreas não consideradas APPs no momento inicial da implantação.

Os equipamentos que permitiriam e incentivariam o uso da área pela população (mirantes, quadras poliesportivas, anfiteatros, quiosques, etc.) foram utilizados como um dos argumentos para justificar a execução do projeto na área proposta, no entanto, em quase quarenta anos ainda não saíram do papel.

Não podemos voltar no tempo, também não é viável ou razoável demolir as ocupações consolidadas, mas podemos utilizar essas considerações para orientar os futuros usos, obedecendo o que estabelece a legislação e garantindo a manutenção da paisagem e das funções ambientais/ecossistêmicas.

Dentre os critérios que asseguram o cumprimento dos objetivos dos instrumentos de ordenamento do Município, desde o Plano Diretor de 1984, estão a proteção, a preservação ou a recuperação do meio ambiente e do patrimônio natural. Alguns argumentam que as áreas descaracterizadas/degradadas são passíveis de ocupação, no entanto, acreditamos que tal argumento não se sustenta, pois, além da previsão legal, existem técnicas e métodos propostos e oficialmente instruídos para recuperar as áreas degradadas e assim garantir a manutenção de 
sua função ambiental. Liberar a ocupação de áreas degradadas é preocupante, pois interessados podem promover a degradação para posterior ocupação. Defendemos que a medida mais adequada é declarar as áreas não ocupadas como áreas non aedificandi, objetivando garantir o valor cênico-paisagístico e a preservação ambiental, conforme $\S 2^{\circ}$ do art. 20 do Plano Diretor de 2007, e que sejam objeto de projetos de recuperação de áreas degradadas - PRAD.

A cidade de Natal, capital do Rio Grande do Norte, possui uma grande beleza natural, tanto que desde o início da década de 1980 a promoção do turismo baseado no atrativo paisagístico tem gerado grande receita. Essa grande beleza que atrai turistas também atrai indivíduos e/ou grupos que não se contentam em contemplá-la, mas desejam se instalar o mais próximo, ou mesmo sobre os elementos da paisagem, descaracterizando-os ou destruindo-os por completo, uma situação de insustentabilidade não apenas ambiental e paisagística, mas também econômica, pois desaparecendo o objeto do interesse, muito provavelmente, também desaparecerá o interessado.

\section{REFERÊNCIAS}

AB’SÁBER, A. N. Litoral do Brasil/Brazilian coast. São Paulo: Metalivros, 2005, 288 p.

ARNOTT, R. D. An introduction to coastal processes and geomorphology. New York: Cambridge University Press, 2010, 432 p.

BERTALANFFY, L. Teoria Geral dos Sistemas. Petrópolis: Editora Vozes, 1975, 351 p.

BERTRAND, G. Paisagem e geografia física global. Esboço metodológico. Revista RA'E GA, Curitiba, n. 8, p. 141-152, 2004.

BIRD, E. Coastal Geomorphology: an introduction. West Sussex: Wiley, 2008, 436 p.

DREW, D. Processos interativos homem-meio ambiente. Rio de Janeiro: Bertrand Brasil, 2011, 212 p.

GUERRA, A. T.; GUERRA, A. J. T. Novo Dicionário Geológico-Geomorfológico. Rio de Janeiro: Bertand Brasil, 1997, 652 p.

Instituto Brasileiro de Geografia e Estatística. Glossário geológico. Rio de Janeiro: IBGE, 1999, 195 p. 
Instituto Brasileiro de Geografia e Estatística. Atlas geográfico das zonas costeiras e oceânicas do Brasil. Rio de Janeiro: IBGE, 2011, 176 p.

JATOBÁ, L.; LINS, R. C. Introdução à geomorfologia. Recife: Bagaço, 1998, 149 p.

LIVINGSTONE, I. WARREN, A. Aeolian Geomorphology: an Introduction. Harlow: Longman, 1996, $211 \mathrm{p}$.

MAYHEW, S. Dictionary of Geography. New York: Oxford University Press, 2004, 551 p.

RODRIGUEZ, J. M. M.; SILVA, E. V.; CAVAlCANTI, A. P. B. Geoecologia das Paisagens: uma visão Geossistêmica da análise ambiental. Fortaleza: Editora UFC, 2007, $222 \mathrm{p}$.

SOUZA, Itamar de. Nova História de Natal. 2 ed. Natal: Departamento Estadual de Imprensa, 2008, 797 p.

SUGUIO, K. Dicionário de geologia sedimentar e áreas afins. Rio de Janeiro: Bertrand Brasil, 1998, 1222 p.

WICANDER, R.; MONROE, J. S. Fundamentos de geologia. São Paulo: Cenage Learning, 2011, 528 p.

Recebido em: 15/08/2018

Aceite para publicação em: 05/11/2018 